\title{
Acetyl salicylic acid inhibits Th17 airway inflammation via blockade of IL- 6 and IL-17 positive feedback
}

\author{
Hyung-Geun Moon ${ }^{1}$, Chil Sung Kang ${ }^{1}$, Jun-Pyo Choi ${ }^{1}$, Dong Sic Choi ${ }^{1}$, Hyun Il Choi ${ }^{1}$, Yong Wook Choi ${ }^{1}$, \\ Seong Gyu Jeon ${ }^{1}$, Joo-Yeon Yoo ${ }^{1}$, Myoung Ho Jang ${ }^{2}$, Yong Song Gho ${ }^{1}$ and Yoon-Keun Kim ${ }^{1}$
}

T-helper (Th)17 cell responses are important for the development of neutrophilic inflammatory disease. Recently, we found that acetyl salicylic acid (ASA) inhibited Th17 airway inflammation in an asthma mouse model induced by sensitization with lipopolysaccharide (LPS)-containing allergens. To investigate the mechanism(s) of the inhibitory effect of ASA on the development of Th17 airway inflammation, a neutrophilic asthma mouse model was generated by intranasal sensitization with LPS plus ovalbumin (OVA) and then challenged with OVA alone. Immunologic parameters and airway inflammation were evaluated 6 and $48 \mathrm{~h}$ after the last OVA challenge. ASA inhibited the production of interleukin (IL)-17 from lung T cells as well as in vitro Th17 polarization induced by IL-6. Additionally, ASA, but not salicylic acid, suppressed Th17 airway inflammation, which was associated with decreased expression of acetyl-STAT3 (downstream signaling of IL-6) in the lung. Moreover, the production of IL-6 from inflammatory cells, induced by IL-17, was abolished by treatment with ASA, whereas that induced by LPS was not. Altogether, ASA, likely via its acetyl moiety, inhibits Th17 airway inflammation by blockade of IL-6 and IL-17 positive feedback.

Experimental \& Molecular Medicine (2013) 45, e5; doi:10.1038/emm.2013.10; published online 18 January 2013

Keywords: Acetyl salicylic acid; IL-6; IL-17A; STAT3; Th17

\section{INTRODUCTION}

Asthma is a complex syndrome with many clinical phenotypes; its major characteristics include a variable degree of airflow obstruction, airway hyperresponsiveness, and eosinophilic or non-eosinophilic inflammation. ${ }^{1}$ Severe persistent and/or difficult-to-control asthma may be associated with neutrophilic airway inflammation, whereas mild and moderate asthma may be related to eosinophilic airway inflammation. ${ }^{1,2}$ In terms of asthma immunopathogenesis, airway inflammation in asthma patients can be categorized according to the involvement of particular $\mathrm{CD} 4{ }^{+} \mathrm{T}$ cell subsets, including T-helper (Th)1, Th2 and Th17. ${ }^{3}$

In the past several years, Th17 cell response has been highlighted as a key player in neutrophilic airway inflammation, and overexpression of interleukin (IL)-17 in airway epithelial cells has been related to neutrophilic airway inflammation. ${ }^{4}$ Additionally, airway exposure to lipopolysaccharide (LPS)-containing allergens induces IL-17-dependent neutrophilic airway inflammation. ${ }^{5}$ IL-6 is a key inducer of
Th17 cell responses in the lung. In terms of Th17 polarization, signal transducer and activator of $\mathrm{T}$ cells (STAT) 3 and retinoid-related orphan receptor (ROR) $\gamma \mathrm{t}$ are important transcription factors. ${ }^{6,7}$ Induction of ROR $\gamma t$ is dependent on STAT3 signaling, which is preferentially activated by IL- $6 .{ }^{8}$

Acetyl salicylic acid (ASA), or aspirin, has been prescribed for the treatment of several inflammatory conditions for several decades. ASA inhibits cyclooxygenase (COX) enzymes, which are related to the production of pro-inflammatory arachidonic acid metabolites. ${ }^{9}$ However, several mechanisms of the anti-inflammatory effects of ASA, other than COX inhibition, have been proposed: ASA inhibits the activity of IкB kinase- $\beta$, thereby preventing activation of nuclear factor$\kappa \mathrm{B}$, which is involved in the pathogenesis of inflammation; ${ }^{10}$ ASA triggers anti-inflammatory 15-epi-lipoxin $\mathrm{A}^{11}$ and induction of apoptosis of inflammatory cells via the mitogen-activated protein kinase pathway; ${ }^{12}$ and ASA inhibits the accumulation of inflammatory cells in an adenosine-dependent manner. ${ }^{13}$

\footnotetext{
${ }^{1}$ Department of Life Science and Division of Molecular and Life Sciences, Pohang University of Science and Technology (POSTECH), Pohang, Republic of Korea and ${ }^{2}$ Division of Integrative Biosciences \& Biotechnology, Pohang University of Science and Technology (POSTECH), Pohang, Republic of Korea Correspondence: Professor Y-K Kim, Department of Life Science and Division of Molecular and Life Sciences, Pohang University of Science and Technology (POSTECH), Pohang 790-784, Republic of Korea.

E-mail: juinea@postech.ac.kr
}

Received 8 June 2012; accepted 24 October 2012 
Previously, we demonstrated that ASA inhibited Th17 inflammation, but enhanced Th2 inflammation in the lung. ${ }^{14}$ In the present study, we aimed to determine the mechanism(s) of the inhibitory effect of ASA on the development of allergeninduced Th17 airway inflammation.

\section{MATERIALS AND METHODS}

Mice

Wild-type (WT) and interferon (IFN)- $\gamma^{-1-}$ C57BL/6 mice were purchased from Jackson Laboratories (Bar Harbor, ME, USA). IL$17 \mathrm{~A}^{-1-}$ and OT-II C57BL/6 mice were kindly donated by Y-C Sung (Pohang University of Science and Technology (POSTECH), Pohang, Republic of Korea). These mice were bred in an animal laboratory at POSTECH. Age- and sex-matched mice were used for control animal experiments. Animal study protocols were approved by the Institutional Animal Care and Use Committee of POSTECH.

\section{Chemicals, recombinant proteins and drugs}

LPS and ovalbumin (OVA) was purchased from Calbiochem (Darmstadt, Germany) and Sigma-Aldrich (St Louis, MO, USA), respectively. Recombinant IL-6 (rIL-6), rIL-12 and rTGF- $\beta 1$ were purchased from R\&D Systems (Minneapolis, MN, USA). ASA (aspirin-lysine) was purchased from Ilyang Pharmaceutical Co. (Yongin-si, Gyeonggi-do, Republic of Korea), and salicylic acid (SA) and celecoxib (a COX2 inhibitor) were purchased from Sigma-Aldrich.

\section{Protocol for the generation of a neutrophilic asthma mouse model}

As an allergen, OVA was used after LPS depletion from the OVA antigen stock, as described previously. ${ }^{15}$ A neutrophilic asthma mouse model was generated as described previously. ${ }^{5}$ Briefly, 6-week-old mice were sensitized intranasally with OVA $(75 \mu \mathrm{g})$ and LPS $(10 \mu \mathrm{g})$ on days $0,1,2$ and 7 and then challenged intranasally with OVA $(50 \mu \mathrm{g})$ alone on days 14, 15, 21 and 22. As a negative control, mice were sensitized with OVA $(75 \mu \mathrm{g})$ alone and then challenged with phosphate-buffered saline (PBS; $30 \mu \mathrm{l}$ ). Drugs (ASA, SA and celecoxib) were administered intraperitoneally on days 14, 15, 21 and once on day 22 right away after the OVA challenge.

\section{Cellularity in bronchoalveolar lavage (BAL) fluids}

BAL fluids were obtained as described previously. ${ }^{15}$ Briefly, mice were anesthetized with ketamine, and the trachea was isolated by blunt dissection. A small-caliber tube was inserted and secured in the airway. Two successive volumes of $0.75 \mathrm{ml}$ PBS were instilled and gently aspirated, and these two volumes were pooled. Each BAL sample was centrifuged, and the supernatants were stored at $-70{ }^{\circ} \mathrm{C}$ until use. The total number of inflammatory cells was counted after re-suspension of the cell pellets with $100 \mu \mathrm{l}$ PBS. After Diff-Quick staining (Dade Behring, Inc., Newark, DE, USA) of the BAL cells in a cytospin preparation, the types of inflammatory cells were determined by counting 300 cells, which were classified as macrophages, lymphocytes, neutrophils or eosinophils, and the percentages of each cell type were calculated.

\section{Intracellular staining of $\mathrm{T}$ cells in lung tissues and lung- draining lymph nodes (LN)}

Cells were isolated from lung tissues and regional LN $\left(4 \times 10^{6} \mathrm{ml}^{-1}\right)$ and were incubated in 48 -well plates coated with anti-CD3 plus antiCD28 antibodies (Abs; $1 \mu \mathrm{g} \mathrm{ml}^{-1}$ each; eBioscience, San Diego, CA,
USA) at $37^{\circ} \mathrm{C}$ for $6 \mathrm{~h}$ and then re-stimulated with Brefeldin $\mathrm{A}$ $\left(10 \mu \mathrm{g} \mathrm{ml}^{-1}\right)$ for $2 \mathrm{~h}$. Cells were stained with surface protein-specific Abs (allophycocyanin-conjugated anti-CD3, fluorescein (FITC)-conjugated anti-CD4 and phycoerythrin-Cy5-conjugated anti-CD8; BD Biosciences, San Jose, CA, USA) for $30 \mathrm{~min}$ at $4{ }^{\circ} \mathrm{C}$ and then fixed for $10 \mathrm{~min}$ in $4 \%$ paraformaldehyde at room temperature. Cells were incubated with $\mathrm{Abs}$ to candidate cytokines (anti-IL-17-PE; BD Biosciences) for $30 \mathrm{~min}$ at room temperature and analyzed on a FACSCalibur flow cytometer (BD Biosciences) and using CellQuest software (BD Biosciences). The number of cells in the lung was determined by multiplying the total number of lung cells by the percentage of $\mathrm{CD} 4{ }^{+} \mathrm{IL}-17 \mathrm{~A}^{+} \mathrm{T}$ cells.

\section{Cytokine production from $\mathrm{T}$ cells after non-specific and allergen-specific stimulation}

Single-cell suspensions from spleens, lung tissues or lung-draining LN were prepared. Cells were incubated with non-specific stimuli (antiCD3 plus anti-CD28 antibodies (Abs)) for $12 \mathrm{~h}$ and with OVA $\left(100 \mu \mathrm{g} \mathrm{ml}^{-1}\right)$ for $72 \mathrm{~h}$. Cytokine levels in supernatants were measured.

\section{Enzyme-linked immunosorbent assay (ELISA)}

IFN- $\gamma$, IL-17, IL-6, tumor necrosis factor- $\alpha$ and monocyte chemotactic protein-1 levels were quantified via ELISA, following the manufacturer's instructions (R\&D Systems).

\section{Preparation of bone marrow dendritic cells (BMDCs)}

BMDCs were prepared by following the methods of Lutz et al. ${ }^{16}$ In brief, bone marrow cells were prepared and cultured in Petri dishes for 3 days with granulocyte/macrophage-colony stimulating factor (GM-CSF; $20 \mathrm{ng} \mathrm{ml}^{-1}$ ). Three days later, $10 \mathrm{ml}$ culture media was added. On days 6 and 8, culture supernatants were collected and then centrifuged. Cells were re-suspended in culture media containing GM-CSF $\left(20 \mathrm{ng} \mathrm{ml}^{-1}\right)$. On day 10 , cells were collected by centrifugation and then re-suspended in culture media with GMCSF $\left(5 \mathrm{ng} \mathrm{ml}^{-1}\right)$.

\section{Antigen uptake by immune cells}

Antigen uptake analysis was conducted in Raw 264.7 cells (macrophage cell lines) and BMDCs using OVA-FITC (Invitrogen, Life Technologies, Grand Island, NY, USA) and the FACSCalibur flow cytometer.

\section{In vitro differentiation}

Splenocytes from WT, OT-II and IFN- $\gamma^{-/-}$mice were prepared as single-cell suspensions. CD4 ${ }^{+} \mathrm{T}$ cells, OT-II CD4 ${ }^{+} \mathrm{T}$ cells and CD11c ${ }^{+}$DCs were isolated by autoMACS (Miltenyi Biotec, Bergisch Gladbach, Germany) from the splenocytes of WT and IFN $-\gamma^{-1-}$ mice. To differentiate Th1 and Th17 subtypes, cells were cultured with mouse rIL-12 $\left(10 \mathrm{ng} \mathrm{ml}^{-1}\right)$, mouse IL-6 $\left(20 \mathrm{ng} \mathrm{ml}^{-1}\right)$ and human TGF- $\beta 1\left(10 \mathrm{ng} \mathrm{ml}^{-1}\right)$ in an anti-CD3 $\left(1 \mu \mathrm{g} \mathrm{ml}^{-1}\right)$ antibody-coated culture plate for 3 days. All Abs were purchased from R\&D Systems. IL-17A production was assayed by ELISA, and the presence of $\mathrm{CD} 4^{+}$ IL-17A ${ }^{+}$T cells was confirmed using the FACSCalibur flow cytometer.

\section{Western blotting and immunoprecipitation assay}

Lung tissues were homogenized with ice-cold RIPA buffer $(50 \mathrm{~mm}$ Tris-HCl, pH 7.5, 1\% NP-40, 0.25\% Na-deoxycholate, $100 \mathrm{~mm} \mathrm{NaCl,}$ $1 \mathrm{~mm}$ EDTA, protease inhibitor). Protein concentrations were determined by the DC protein assay kit (Bio-Rad, Hercules, CA, USA) using bovine serum albumin as a standard. The lung lysates were 
separated by sodium dodecyl sulfate-polyacrylamide gel electrophoresis and transferred to polyvinylidene fluoride membranes. The blocked membrane was then incubated with the antibodies indicated, including those against actin (Santa Cruz Biotechnology, Santa Cruz, CA, USA), ROR $\gamma \mathrm{t}$ (BioLegend, San Diego, CA, USA), STAT3 (Cell Signaling Technology), phospho-STAT3 (pSTAT3) (Cell Signaling Technology), acetyl lysine (Abcam, Cambridge, UK) and streptavidin-POD (Roche, Mannheim, Germany). Immunoreactive bands were visualized using a chemiluminescent substrate. For immunoprecipitation assays, lung lysates were incubated with STAT3 antibody-immobilized beads (Cell Signaling Technology) overnight, washed with ice-cold RIPA buffer and eluted in $2 \times$ SDS loading dye.

\section{Statistical analysis}

Significant differences between the treatments were assessed using Student's $t$-test, analysis of variance or Wilcoxon's rank-sum test. For multiple comparisons, analysis of variance was first used, and if significant differences were found, individual $t$-tests or Wilcoxon's rank-sum tests for pairs of groups were then performed.

\section{RESULTS}

\section{Effects of ASA on the development of Th17 airway} inflammation in IFN- $\boldsymbol{\gamma}$-deficient mice

Previous experimental evidence indicated that ASA treatment during allergen challenge inhibited Th17 airway inflammation, but not Th1 inflammation, in a neutrophilic asthma model

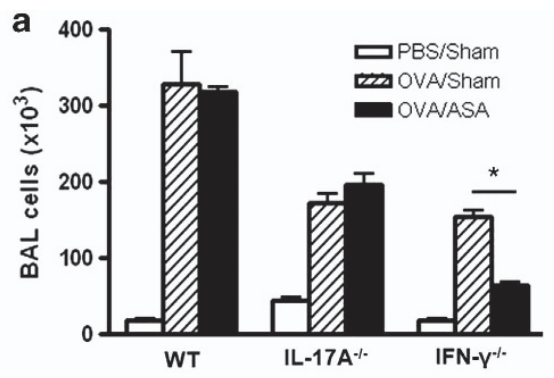

induced by airway sensitization with LPS-containing allergens. ${ }^{14}$ To further delineate the effect of ASA on the development of Th17 airway inflammation, the neutrophilic asthma model was developed in IFN- $\gamma^{-1-}$ and IL17A ${ }^{-1-}$ mice with and without treatment of ASA $\left(18 \mathrm{mg} \mathrm{kg}^{-1}\right)$. In the present study, BAL cellularity analysis $24 \mathrm{~h}$ after the last OVA challenge showed that lung infiltration of inflammatory cells induced by sensitization with LPS-containing OVA was significantly lower in IFN- $\gamma^{-1}$ mice treated with ASA than in IFN $-\gamma^{-l-}$ mice treated with a sham control, whereas this phenotype was similar in IL-17A ${ }^{-1-}$ and WT mice after ASA treatment compared to sham treatment (Figure 1a). Based on the finding that the inhibitory effect of ASA on the development of airway inflammation was prominent in IFN- $\gamma^{-/-}$ mice, we further analyzed the therapeutic effects of ASA in IFN $-\gamma^{-l}$ mice. BAL cellularity analysis $48 \mathrm{~h}$ after the last OVA challenge showed that lung infiltration of macrophages, lymphocytes, neutrophils and eosinophils induced by sensitization with LPS-containing OVA was significantly inhibited by ASA treatment compared to sham treatment (Figure 1b). The present study showed that IL-17A levels in the culture supernatants of lung cells after stimulation with anti-CD3 plus anti-CD28 antibodies and also with OVA were enhanced in OVA-challenged mice compared to PBS-challenged mice; this
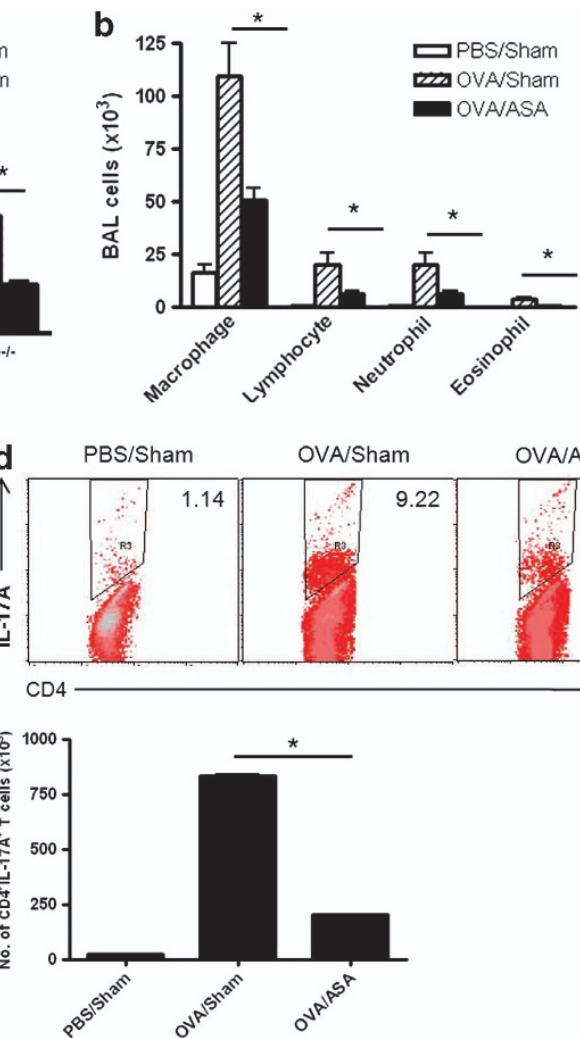

Figure 1 Acetylsalicylic acid (ASA) inhibits T-helper 17 inflammation in the lung. Wild-type (WT), interleukin (IL)-17A-/- and interferon (IFN) $\gamma^{-1}$ - mice were sensitized intranasally with lipopolysaccharide (LPS) $(10 \mu \mathrm{g})$ plus ovalbumin (OVA) $(75 \mu \mathrm{g})$ and then challenged with OVA $(50 \mu \mathrm{g})$ alone. Evaluation ( $n=5$ per group) was performed $48 \mathrm{~h}$ after the last OVA challenge. (a) Infiltrated bronchoalveolar lavage (BAL) cells by OVA provocation with or without ASA administration in WT, IL-17A ${ }^{-1-}$ and IFN- $\gamma^{-1-}$ mice. (b) BAL cellularity in IFN- $\gamma^{-l-}$ mice. (c) Level of IL-17 A production after re-stimulation by anti-CD3 plus anti-CD28 or OVA in IFN- $\gamma^{-l-}$ mice. (d) Flow cytometry analysis of $\mathrm{CD} 4+\mathrm{IL}-17 \mathrm{~A}^{+} \mathrm{T}$ cells, and the number of $\mathrm{CD} 4+\mathrm{IL}-17 \mathrm{~A}^{+} \mathrm{T}$ cells in the lung tissue of IFN- $\gamma^{-/-}$mice. PBS, phosphate-buffered saline. ${ }^{*} P<0.05$. 
increased production was significantly inhibited by ASA treatment (Figure 1c). In addition, the number of Th17 cells in the lung tissue, enhanced by OVA challenge, was significantly decreased by ASA treatment, but not by sham treatment (Figure 1d). Collectively, these findings suggested that ASA suppressed lung infiltration of Th17 cells and Th17 inflammation, especially in an IFN- $\gamma$-deficient state.

\section{Effects of ASA on the development of IL-6-induced Th17 polarization}

IL-6, along with TGF- $\beta 1$, is a well-known key mediator of Th17 polarization. ${ }^{8}$ We aimed to evaluate the effect of ASA on Th17 polarization of naive $\mathrm{T}$ cells. To test this, naive splenocytes were isolated from WT and IFN- $\gamma^{-1-}$ mice, and rIL-6 $\left(20 \mathrm{ng} \mathrm{ml}^{-1}\right)$ and rTGF- $\beta 1\left(10 \mathrm{ng} \mathrm{ml}^{-1}\right)$ were added to the splenocytes followed by incubation in an anti-CD3 $(1 \mu \mathrm{g})$ coated plate for 3 days. ${ }^{17}$ Anti-CD3-stimulated IL-17A production from splenocytes, enhanced by IL- 6 and TGF- $\beta 1$, was diminished by ASA treatment in a dose-dependent manner in both WT and IFN- $\gamma^{-1-}$ mice (Figure $2 \mathrm{a}$ ). In terms of the effect of ASA on Th1 polarization, the present study showed that the production of IFN- $\gamma$ from WT splenocytes was enhanced by rIL-12 $\left(10 \mathrm{ng} \mathrm{ml}^{-1}\right)$, but was not affected by ASA treatment (Figure 2b). Next, we isolated $\mathrm{CD} 4^{+} \mathrm{T}$ cells from WT splenocytes and then cultured the cells with rIL-6 $\left(20 \mathrm{ng} \mathrm{ml}^{-1}\right)$ and rTGF- $\beta 1\left(10 \mathrm{ng} \mathrm{ml}^{-1}\right)$ with or without treatment with ASA $(1000 \mathrm{nM})$ in anti-CD3 antibody-coated plates for 3 days. Data suggested that IL-17A production from $\mathrm{CD}^{+}{ }^{+} \mathrm{T}$ cells, induced by IL- 6 and TGF- $\beta 1$, was significantly inhibited by ASA treatment (Figure 2c). Furthermore, CD4 ${ }^{+}$ $\mathrm{T}$ cells were isolated from OT-II splenocytes and CD11c ${ }^{+} \mathrm{DCs}$ were isolated from IFN- $\gamma^{-1}$ splenocytes, and then $\mathrm{CD} 4{ }^{+} \mathrm{T}$ cells, CD11c ${ }^{+}$DCs and SIINFEKL (an OT-II-specific peptide; $10 \mu \mathrm{g}$ ) were co-cultured in Th17-driving conditions for 3 days. IL-17A production from OT-II CD $4{ }^{+} \mathrm{T}$ cells was significantly enhanced by Th17-polarizing conditions, and this enhanced production was significantly inhibited by ASA treatment (Figure 2d). In addition, the number of Th17 cells was found to be enhanced by TGF- $\beta 1$ and IL-6; this increase was abolished by ASA treatment (Figure 2e). Collectively, these data suggest that ASA suppressed Th17 polarization induced by IL- 6 and TGF- $\beta 1$, but not Th1 polarization induced by IL- 12 .

\section{Effects of the acetyl moiety of ASA on the development of Th17 cell responses}

The first known mechanism of action of ASA was the inhibition of COX1 and COX2 via acetylation of these enzymes. ${ }^{9}$ To investigate the effect of COX2 inhibition by the acetyl moiety of ASA on the development of Th17 airway inflammation, the therapeutic effect of SA, with no acetyl moiety, and of celecoxib (a selective COX2 inhibitor) was
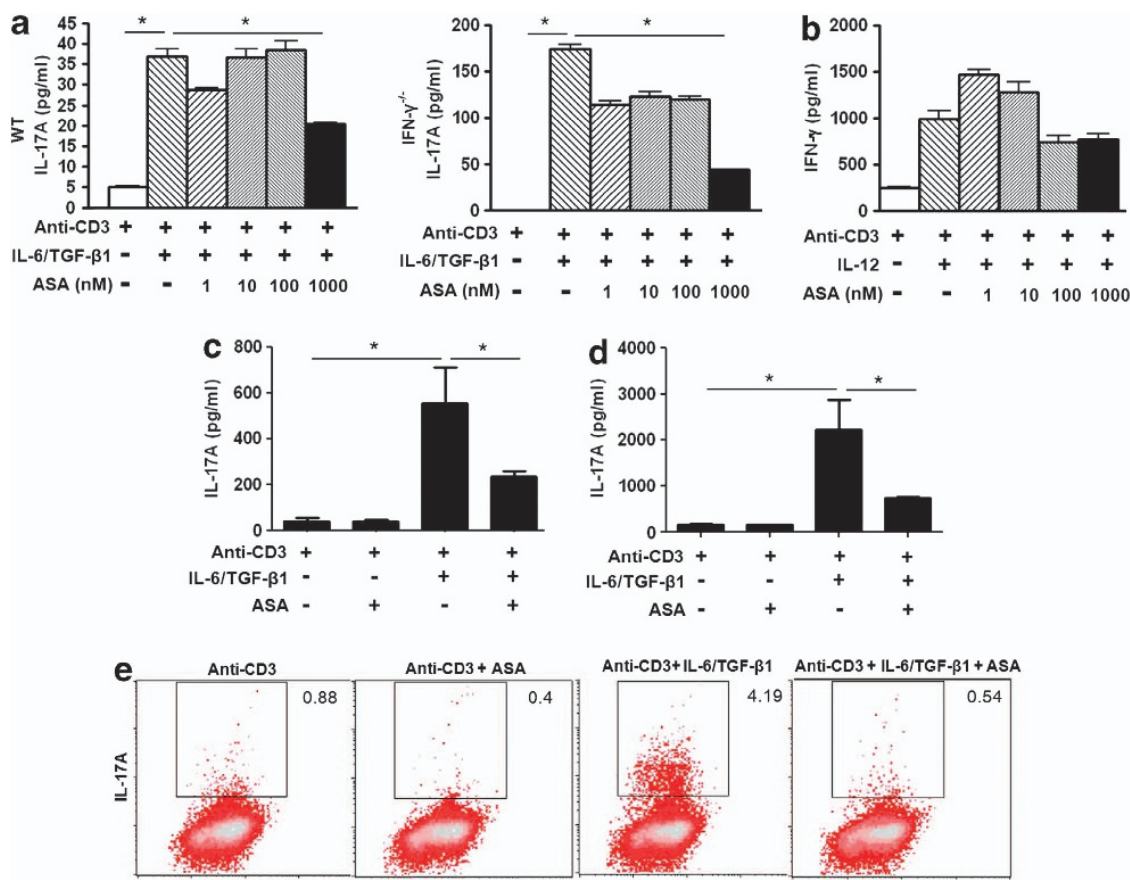

Figure 2 Acetylsalicylic acid (ASA) inhibits T-helper (Th)17 polarization induced by interleukin (IL)- 6 and transforming growth factor (TGF)- $\beta 1$. (a, b) Naive splenocytes were isolated from wild-type (WT) and interferon (IFN)- $\gamma^{-1-}$ mice and then polarized with IL- 6 and TGF- $\beta 1$ for 3 days. The level of IL-17A produced by WT and IFN- $\gamma^{-1-}$ splenocytes is shown after stimulation with recombinant IL- 6 $(\mathrm{rlL}-6)\left(20 \mathrm{ng} \mathrm{ml}^{-1}\right)$ plus rTGF- $\beta 1\left(10 \mathrm{ng} \mathrm{ml}^{-1}\right)$, anti-CD3 $(1 \mu \mathrm{g})$ or different doses of ASA, and the level of IFN- $\gamma$ by $\mathrm{rlL}^{-12}\left(10 \mathrm{ng} \mathrm{ml}^{-1}\right)$. (c-e) $\mathrm{CD}^{+}{ }^{+} \mathrm{T}$ cells and $\mathrm{CD} 11 \mathrm{c}^{+}$dendritic cells (DCs) were isolated using autoMACS. (c) The level of IL-17A produced by WT CD4 ${ }^{+} \mathrm{T}$ cells is shown after stimulation with anti-CD3 $\left(10 \mu \mathrm{g} \mathrm{ml}^{-1}\right)$, rlL-6 (20 $\left.\mathrm{ng} \mathrm{ml}^{-1}\right)$ plus rTGF- $\beta 1$ (10 $\left.\mathrm{ng} \mathrm{ml}^{-1}\right)$ or ASA (1000 nm) for 3 days. (d) The level of IL-17A produced from co-cultured OT-II CD4 ${ }^{+} \mathrm{T}$ cells, CD11c ${ }^{+} \mathrm{DCs}$ and SIINFEKL is shown after culture in Th17-differentiating conditions for 3 days. (e) Flow cytometric analysis of the cells in panel (c). ${ }^{*} P<0.05$. 
evaluated in the neutrophilic asthma model. SA $\left(15 \mathrm{mg} \mathrm{kg}^{-1}\right)$ and celecoxib (10 $\left.\mathrm{mg} \mathrm{kg}^{-1}\right)$ were administered intraperitoneally during OVA challenge in $\mathrm{IFN}-\gamma^{-1-}$ mice. BAL cellularity analysis showed that lung infiltration of inflammatory cells, especially neutrophils, was markedly inhibited by ASA, partially inhibited by celecoxib, but not affected by SA treatment (Figure 3a). Similarly, anti-CD3/ $\mathrm{CD} 28$-induced IL-17A production from $\mathrm{T}$ cells in lungdraining LN was found to be significantly reduced by ASA or celecoxib treatment, but not by SA (Figure 3b). These data suggest that the acetyl moiety of ASA was important in the inhibition of Th17 airway inflammation, possibly via COX2 inhibition.

We also evaluated the effects of these drugs on the expression of ROR $\gamma$ t, STAT3, pSTAT3 and acetyl-STAT3 in lung tissues from IFN- $\gamma^{-1}$ mice after OVA challenge, as shown in Figure 3c. This study showed that ASA inhibited the expression of acetyl-STAT3, but not of pSTAT3 or ROR $\gamma$ t. In addition, celecoxib was found to diminish the expression of acetyl-STAT3 and also of pSTAT3 and ROR $\gamma$ t. In contrast, the expression of acetyl-STAT3, pSTAT3 and ROR $\gamma \mathrm{t}$ was not affected by SA treatment, although STAT3 expression was enhanced. To summarize, these findings suggest that the acetyl moiety of ASA inhibited the Th17 cell response possibly via downregulation of acetyl-STAT3 expression.
Effect of ASA on the in vitro production of IL-6 induced by LPS or IL-17

Among the innate immune cells, DCs orchestrate the fate of naive $\mathrm{CD} 4{ }^{+} \mathrm{T}$ cells into Th1, Th2, Th17 or Treg cells. ${ }^{18}$ To investigate the effect of ASA on the development of LPSinduced innate immune responses from antigen-presenting cells, BMDCs were prepared following the method of Lutz et al. ${ }^{16}$ and stimulated with LPS $\left(10 \mathrm{ng} \mathrm{ml}^{-1}\right)$. First, we evaluated the effect of ASA on in vitro antigen uptake by BMDCs and used OVA-FITC as an antigen. The current study showed that LPS did not enhance the uptake of OVA by BMDCs; this phenotype was also unaffected by ASA treatment, irrespective of ASA dose (Figure 4A). Next, the effect of ASA on the expression of co-stimulatory molecules on BMDCs was evaluated. This study showed that the expression of costimulatory molecules, such as MHCII, CD11b and CD80 enhanced by LPS, was not inhibited by ASA treatment, irrespective of ASA dose (Figure 4b). In terms of the production of IL-6 (a Th17-polarizing cytokine), data indicated that IL-6 production from BMDCs was enhanced by LPS, but not inhibited by ASA treatment, irrespective of its dose (Figure 4c).

IL-17A secreted from CD4 ${ }^{+} \mathrm{T}$ cells induces the production of IL-6 from inflammatory cells, such as macrophages and neutrophils, ${ }^{19}$ and rIL-17 induces the production of IL-6 in
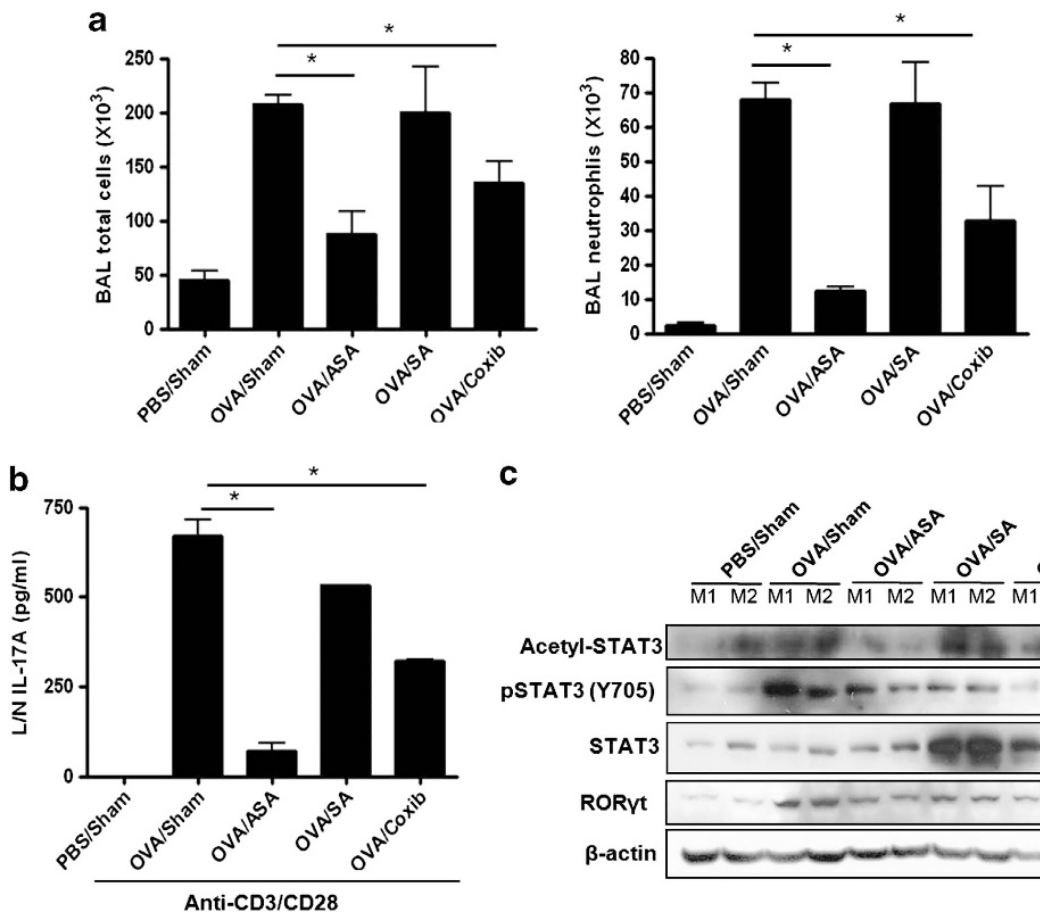

C

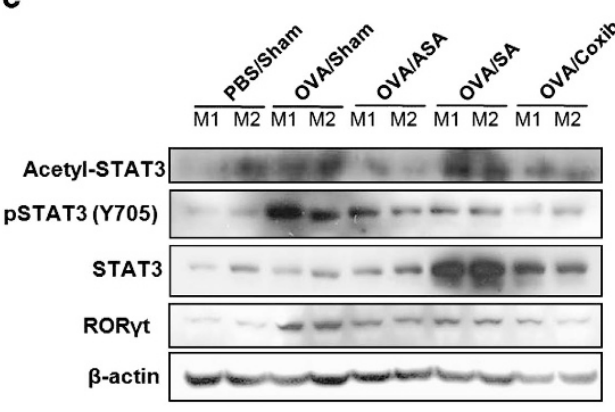

Figure 3 Th17 inflammation in the lung is not inhibited by salicylic acid (SA) treatment. Acetylsalicylic acid (ASA), SA and celecoxib (Coxib) were administered intraperitoneally during ovalbumin (OVA) challenge in the neutrophilic asthma model. (a) Bronchoalveolar lavage (BAL) cellularity in interferon (IFN)- $\gamma^{-l-}$ mice. (b) Level of interleukin (IL)-17A production from lung-draining lymph node (LN) cells, which were stimulated with anti-CD3 plus anti-CD28 in IFN- $\gamma^{-1}$ mice. (c) Western blotting of signal tranducer and activator of transcription 3 (STAT3), pSTAT3, acetyl-STAT3 and retinoid-related orphan receptor (ROR) $\gamma$ t levels in lung tissue. PBS, phosphatebuffered saline. ${ }^{*} P<0.05$. 
Th17-derived autoimmune hepatitis. ${ }^{20}$ To elucidate the effect of ASA on the production of IL-6 induced by IL-17, Raw 264.7 cells were stimulated with LPS $\left(10 \mathrm{ng} \mathrm{ml}^{-1}\right)$ and rIL-17A $\left(50 \mathrm{ng} \mathrm{ml}^{-1}\right)$. Data suggested that IL-6 production was enhanced to a greater degree by LPS plus rIL-17A compared to LPS alone; interestingly, the production of IL- 6 enhanced by rIL-17A, but not by LPS, was inhibited by ASA treatment (Figure 4d). These data suggest that ASA suppressed the production of IL-6 from inflammatory cells, especially macrophages, induced by Th17 cells.

\section{Effect of ASA on the in vivo production of IL-6 induced} by LPS or IL-17

Based on the above data, we evaluated the effect of ASA on the development of in vivo innate immune responses induced by LPS. To test this, LPS $(10 \mu \mathrm{g})$ was administered intranasally into the mouse airway for 3 days with and without treatment of ASA $\left(18 \mathrm{mg} \mathrm{kg}^{-1}\right)$ once a day, and then the mice were evaluated $24 \mathrm{~h}$ later. BAL cellularity analysis showed that lung infiltration of inflammatory cells was enhanced by LPS, but not affected by ASA treatment (Figure 5a). Additionally, IL-6 production, enhanced by LPS, was not inhibited by ASA treatment (Figure 5b). Moreover, the present study showed that co-stimulatory molecule (CD11b, CD80 and CD86) expression by lung DCs, enhanced by LPS, was not inhibited by ASA treatment (Figure $5 \mathrm{c}$ ). Taken together, these data suggest that ASA did not modulate in vivo innate immune responses induced by airway exposure to LPS.

Finally, we evaluated the effect of ASA on the in vivo development of airway inflammation and IL-6 production induced by airway exposure to rIL-17A. To test this, LPS $(10 \mu \mathrm{g})$ was administered intranasally into the mouse airway with or without rIL-17A $\left(2.5 \mu \mathrm{g} \mathrm{kg}{ }^{-1}\right)$. BAL cellularity analysis showed that lung infiltration of neutrophils was significantly increased by LPS plus rIL-17A exposure rather than by LPS exposure alone; interestingly, neutrophil infiltration induced
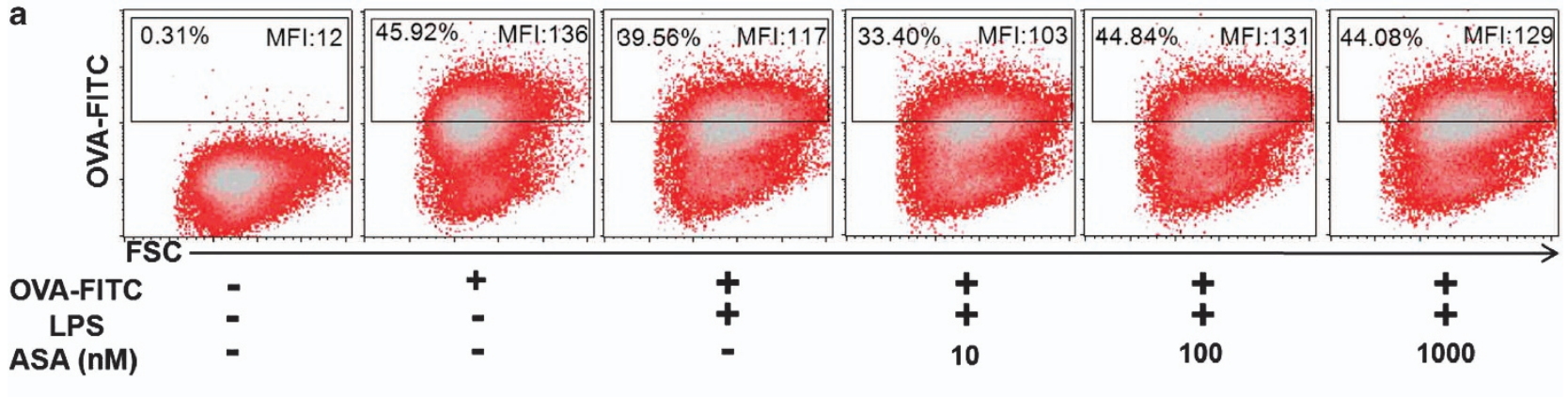

b
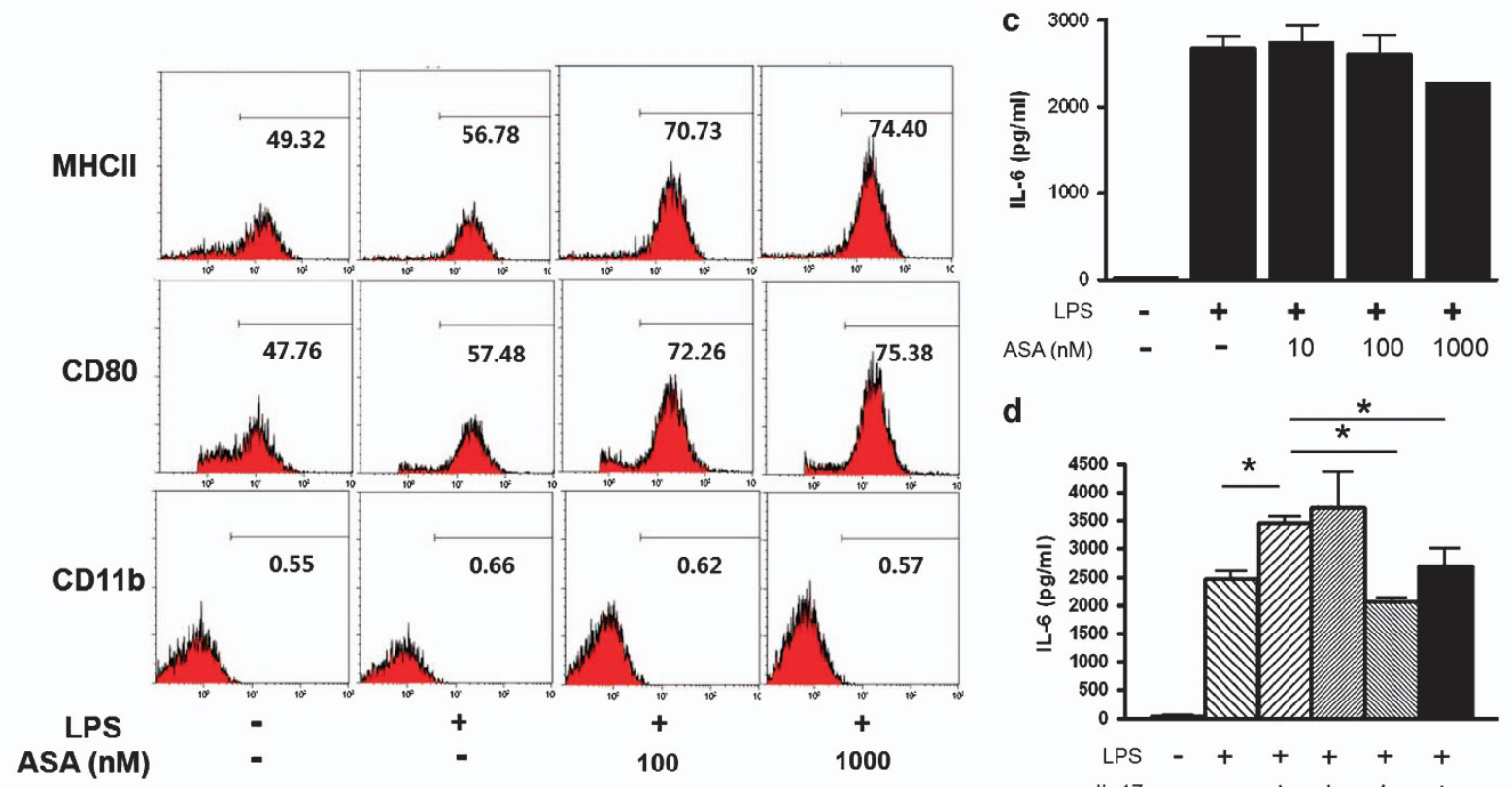

d

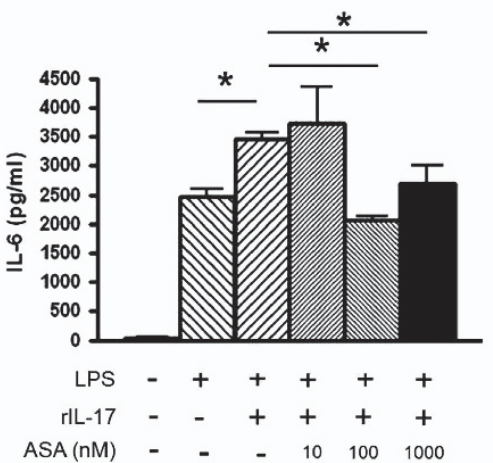

Figure 4 In vitro production of interleukin (IL)-6 induced by IL-17A, but not by lipopolysaccharide (LPS), is inhibited by acetylsalicylic acid (ASA) treatment. (a) Antigen (ovalbumin (OVA)) uptake by bone marrow dendritic cells (BMDCs) after stimulation with LPS and different doses of ASA. (b) Flow cytometric analysis of BMDC maturation. BMDCs were stimulated with LPS (10 ng ml-1) and ASA and then stained with anti-CD11c, anti-MHCII, anti-CD11b, and anti-CD80 antibodies. (c) Level of IL-6 in the culture supernatants of BMDCs stimulated with LPS $\left(10 \mathrm{ngml}^{-1}\right)$ and ASA. (d) Level of IL-6 in the culture supernatants of Raw 264.7 cells activated by LPS $\left(10 \mathrm{ng} \mathrm{ml}^{-1}\right)$, rlL-17A $\left(50 \mathrm{ng} \mathrm{ml}^{-1}\right)$ or ASA. FITC, fluorescein. ${ }^{*} P<0.05$. MFI, mean fluorescent intensity. 
by rIL-17A, but not by LPS, was completely inhibited by ASA treatment (Figure 5d). Similarly, the current study showed that IL-6 production induced by rIL-17A, but not by LPS, was inhibited by ASA treatment (Figure 5e). Collectively, these data suggest that ASA inhibited Th17 airway inflammation, partly via downregulation of IL-6 production in macrophages induced by Th17 cells.

\section{DISCUSSION}

Since it was highlighted in the literature several years ago, various diseases have been explained by Th17 inflammation, such as multiple sclerosis, rheumatoid arthritis, atherosclerosis, inflammatory bowel disease, asthma and even certain cancers. ${ }^{19}$ Our previous data demonstrated that ASA inhibited Th17 airway inflammation. ${ }^{14}$ In the present study, we aimed to elucidate the mechanism(s) of action of the inhibitory effect of ASA on the development of allergen-induced Th17 inflammation in the lung. The present study showed that ASA inhibited Th17 airway inflammation via suppression of IL-6 and IL-17 positive feedback, that is, IL-6-induced Th17 polarization and Th17 cell-induced IL- 6 production.

In humans, IL-1 $\beta$, IL- 6 and IL-23 are the key cytokines that induce Th17 polarization, whereas IL- $1 \beta$, IL- 6 and TGF- $\beta 1$ are crucial in mice. ${ }^{19,21}$ In addition, IL-21, IL-22 and IL-23 are important for maintenance of Th17 cell responses in both humans and mice. ${ }^{8,21}$ In the driving conditions of Th17 polarization in mouse airways, IL-6 leads to induction of a Th17 cell response. ${ }^{8}$ A previous study also indicated that airway exposure to LPS-containing allergens induced Th17 cell responses via the VEGF-IL-6 pathway. ${ }^{5}$ In the present study, ASA was found to inhibit Th17 polarization induced by IL-6, although IL-6 production induced by LPS was not altered by ASA treatment. Collectively, these data indicate that ASA inhibits Th17 polarization induced by IL-6.
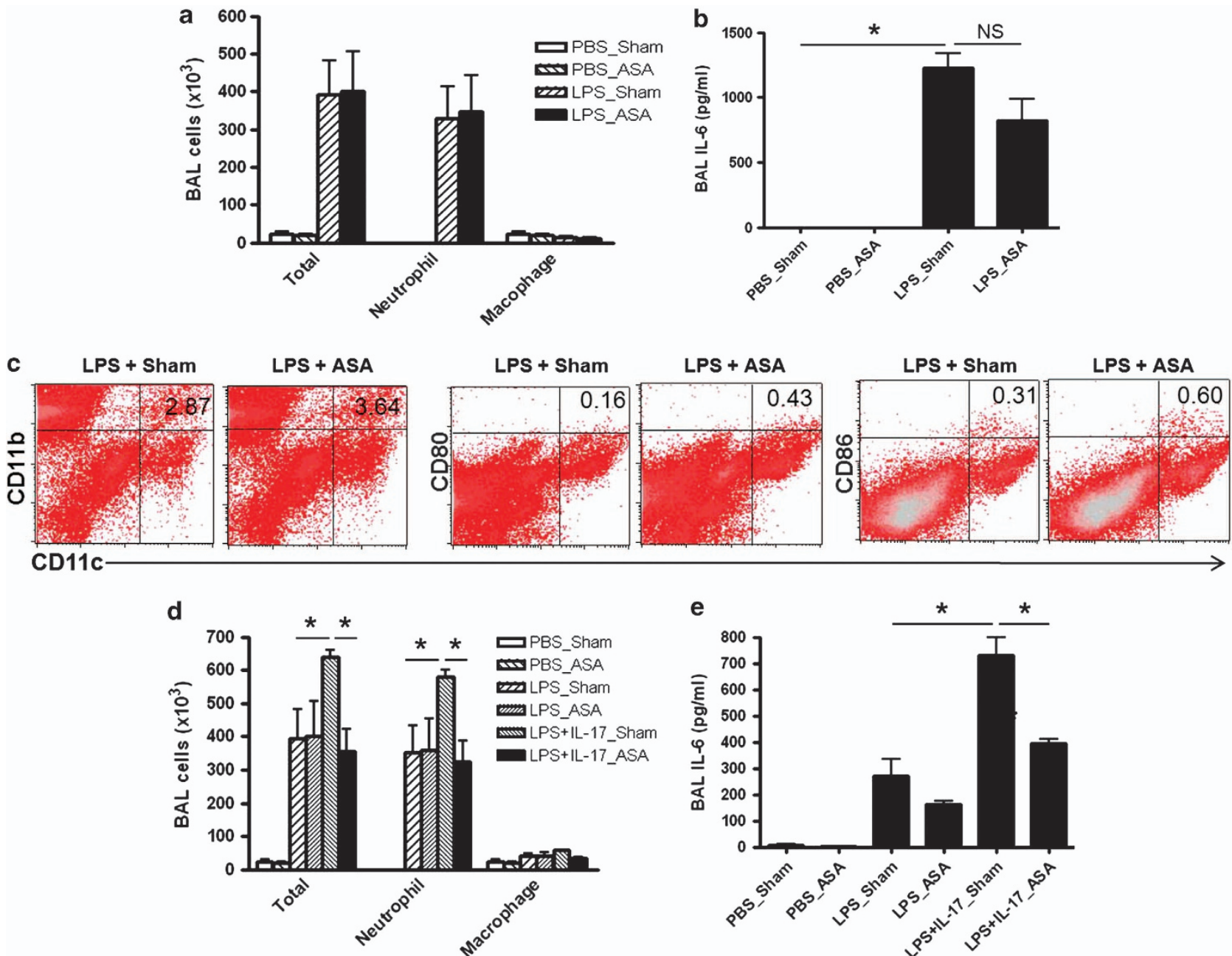

Figure 5 In vivo production of interleukin (IL)-6 induced by IL-17A, but not by lipopolysaccharide (LPS), is inhibited by acetylsalicylic acid (ASA) treatment. (a-c) LPS was administered into wild-type mouse airways for 3 days with and without intraperitoneal treatment with ASA. (a) Bronchoalveolar lavage (BAL) cellularity. (b) BAL IL-6 levels. (c) Flow cytometric analysis of lung dendritic cell (DC) maturation. Lung DCs were stained with anti-CD11c, anti-CD11b, anti-CD80 and anti-CD86 Abs. (d, e) LPS and rIL-17 were administered into WT mouse airways for 3 days with and without intraperitoneal treatment with ASA. (d) BAL cellularity. (e) IL-6 levels in BAL fluid. PBS, phosphate-buffered saline. ${ }^{*} P<0.05$. 
STAT3 is known to be a primary player in the pathway downstream of IL- $6 .{ }^{22}$ pSTAT3 is the active form of the molecule, which induces pro-inflammatory gene expression. ${ }^{23}$ Thus, pSTAT3 has been considered as a marker of Th17 development. On the other hand, the mechanisms of action of $\operatorname{ROR} \alpha, \beta$ and $\gamma$, in addition to their physiological functions and potential role in several pathologies, were elucidated within the last few years. ${ }^{24}$ Among ROR family members, ROR $\gamma$ t is a STAT3 downstream signaling molecule and essential for lineage specification of naive $\mathrm{CD} 4^{+} \mathrm{T}$ cells into Th17 cells. ${ }^{6,7,24}$ However, the present study showed that ASA did not affect the expression of pSTAT3 or ROR $\gamma \mathrm{t}$. These findings suggest that ASA inhibited IL-6-induced Th17 polarization via pathways other than pSTAT3 and ROR $\gamma \mathrm{t}$.

The acetyl moiety of ASA is known to inhibit the functions of COX enzymes via acetylation. ${ }^{9}$ The present study aimed to evaluate the effect of the acetyl moiety of ASA on the development of Th17 airway inflammation by comparison with SA. Data suggested that ASA inhibited IL-6-induced Th17 cell responses, whereas SA did not. Recently, acetyl-STAT3 has been suggested to also be an active form of STAT3. ${ }^{25}$ Acetylation of STAT3 at Lys685 can be induced by IL-6 via PI3K/Akt activation. ${ }^{26}$ Interestingly, the current study showed that the expression of acetyl-STAT3 was diminished by ASA treatment, but not by SA. To sum up, these data suggest that the acetyl moiety of ASA inhibited IL-6-induced Th17 cell responses, possibly via blockade of acetyl-STAT3 expression.

IL- 6 is also a downstream mediator of Th17 cell responses. ${ }^{14}$ IL-17A interacts with IL-17RA or IL-17RC, which transmits signals to TRAF-6-dependent or -independent pathways. ${ }^{27-29}$ The present study showed that the production of IL-6, which was enhanced by IL-17A, was suppressed by ASA treatment. Taking into consideration the fact that ASA inhibited IL-6induced Th17 polarization, the above data indicate that ASA inhibited the development of Th17 airway inflammation via blockade of IL-6 and IL-17A positive feedback.

In summary, the present study indicates that ASA selectively suppresses Th17 airway inflammation, but not Th1-mediated inflammation, in a neutrophilic asthma model. Furthermore, ASA inhibits IL-6-induced Th17 polarization, which is related to the downregulation of acetyl-STAT3 expression. Additionally, ASA blocks IL-17A-induced inflammation and IL-6 production. Thus, ASA can be used to treat Th17dominant neutrophilic asthma.

\section{CONFLICT OF INTEREST}

The authors declare no conflict of interest.

\section{ACKNOWLEDGEMENTS}

We thank Jee-In Lim for providing secretarial assistance and members of the POSTECH animal facility for their help with the animal experiments. This study was supported by the National Research Foundation of Korea funded by the Ministry of Education, Science and Technology (20120008992).
1 Busse WW, Lemanske RFJ. Asthma. N Engl J Med 2001; 344: 350-362.

2 Bateman ED, Hurd SS, Barnes PJ, Bousquet J, Drazen JM, FitzGerald M et al. Global strategy for asthma management and prevention: GINA executive summary. Eur Respir J 2008; 31: 143-178.

3 Soroosh P, Doherty TA. Th9 and allergic disease. Immunology 2009; 127 : 450-458.

4 Park H, Li Z, Yang XO, Chang SH, Nurieva R, Wang YH et al. A distinct lineage of $\mathrm{CD} 4 \mathrm{~T}$ cells regulates tissue inflammation by producing interleukin 17. Nat Immunol 2005; 6: 1133-1141.

5 Kim YS, Hong SW, Choi JP, Shin TS, Moon HG, Choi EJ et al. Vascular endothelial growth factor is a key mediator in the development of T cell priming and its polarization to type 1 and type $17 \mathrm{~T}$ helper cells in the airways. J Immunol 2009; 183: 5113-5120.

6 Ivanov II, McKenzie BS, Zhou L, Tadokoro CE, Lepelley A, Lafaille JJ et al. The orphan nuclear receptor ROR $\gamma$ t directs the differentiation program of proinflammatory IL-17+ T helper cells. Cell 2006; 126: 1121-11233.

7 Yang XP, Ghoreschi K, Steward-Tharp SM, Rodriguez-Canales J, Zhu J, Grainger JR et al. Opposing regulation of the locus encoding IL-17 through direct, reciprocal actions of STAT3 and STAT5. Nat Immunol 2011; 12: 247-254.

8 Korn T, Bettelli E, Oukka M, Kuchroo VK. IL-17 and Th17 cells. Annu Rev Immunol 2009; 27: 485-517.

9 Vane JR. Inhibition of prostaglandin synthesis as a mechanism of action for aspirin-like drugs. Nature $1971 ; 231$ : 232-235.

10 Yin M-J, Yamamoto Y, Gaynor RB. The anti-inflammatory agents aspirin and salicylate inhibit the activityof IkB kinase- $\beta$. Nature 1998; 396: 77-80.

11 Clària J, Serhan CN. Aspirin triggers previously undescribed bioactive eicosanoids by human endothelial cell-leukocyte interactions. Proc Natl Acad Sci USA 1995; 92: 9475-9479.

12 Schwenger P, Bellosta P, Vietor I, Basilico C, Skolnik EY, Vilcek J. Sodium salicylate induces apoptosis via p38 mitogen-activated protein kinase but inhibits tumor necrosis factor-induced c-Jun N-terminal kinase/stressactivated protein kinase activation. Proc Natl Acad Sci USA 1997; 94: 2869-2873.

13 Cronstein BN, Montesinos MC, Weissmann G. Salicylates and sulfasalazine, but not glucocorticoids, inhibit leukocyte accumulation by an adenosine-dependent mechanism that is independent of inhibition of prostaglandin synthesis and p105 of NFkappaB. Proc Natl Acad Sci USA 1999; 96: 6377-6381.

14 Moon HG, Tae YM, Kim YS, Jeon SG, Oh SY, Gho YS et al. Conversion of Th17-type into Th2-type inflammation by acetyl salicylic acid via the adenosine and uric acid pathway in the lung. Allergy 2010; 65: 1093-1103.

15 Kim YK, Oh SY, Jeon SG, Park HW, Lee SY, Chun EY et al. Airway exposure levels of lipopolysaccharide determine type 1 versus type 2 experimental asthma. J Immunol 2007; 178: 5375-5382.

16 Lutz MB, Kukutsch N, Ogilvie AL, Rössner S, Koch F, Romani N et al. An advanced culture method for generating large quantities of highly pure dendritic cells from mouse bone marrow. J Immunol Methods 1999; 223. 77-92.

17 Sutton CE, Lalor SJ, Sweeney CM, Brereton CF, Lavelle EC, Mills KHG. Interleukin-1 and IL-23 induce innate IL-17 production from $\gamma \delta$ T cells, amplifying Th17 responses and autoimmunity. Immunity 2009; 31: 331-341.

18 Guermonprez P, Valladeau J, Zitvogel L, Théry CS, Amigorena S. Antigen presentation and T cell stimulation by dendritic cells. Annu Rev Immunol 2002; 20: 621-667.

19 Weaver CT, Hatton RD, Mangan PR, Harrington LE. IL-17 family cytokiens and the expanding diversity of effector T cell leneages. Annu Rev Immunol 2007; 25: 821-852.

20 Zhao L, Tang Y, You Z, Wang Q, Liang S, Han X et al. Interleukin-17 contributes to the pathogenesis of autoimmune hepatitis through inducing hepatic interleukin-6 expression. PloS One 2011; 19: e18909.

21 Francesco F, Romagnani S. Do studies in humans better depict Th17 cells? Blood 2009; 114: 2213-2219.

22 Gao H, Ward PA. STAT3 and suppressor of cytokine signaling 3: potential targets in lung inflammatory responses. Expert Opin Ther Targets 2007; 11: 869-880.

23 Scott MJ, Godshall CJ, Cheadle WG. STATs, cytokines, and sepsis. Clin Diagn Lab Immunol 2002; 9: 1153-1159.

24 Jetten AM. Retinoid-related orphan receptors (RORs): critical roles in development, immunity, circadian rhythm, and cellular metabolism. Nucl Recept Signal 2009; 7: 1-32. 
25 Yuan ZL, Guan YJ, Chatterjee D, Chin YE. STAT3 dimerization regulated by reversible actylation of a single lysine residue. Science 2005; 307 : 269-273.

26 Ohbayashi N, Ikeda O, Taira N, Yamamoto Y, Muromoto R, Sekine Y et al. LIF- and IL-6-induced acetylation of STAT3 at Lys-685 through PI3K/Akt activation. Biol Pharm Bull-4 2007; 30: 1860.

27 Zepp J, Wu L, Li X. IL-17 receptor signaling and T helper 17-mediated autoimmune demyelinating disease. Trends Immunol 2011; 32: 232-239.

28 Chang SH, Dong C. Signaling of interleukin-17 family cytokines in immunity and inflammation. Cell Signal 2011; 23: 1069-1075.
29 Qian Y, Liu C, Hartupee J, Altuntas CZ, Gulen MF, Jane-Wit D et al. The adaptor Act1 is required for interleukin 17-dependent signaling associated with autoimmune and inflammatory disease. Nat Immunol 2007; 8: 247-256.

\section{This work is licensed under a Creative Commons} Attribution-NonCommercial-NoDerivs 3.0 Unported License. To view a copy of this license, visit http:// creativecommons.org/licenses/by-nc-nd/3.0/ 